\title{
Combination of RNAseq and SNP nanofluidic array reveals the center of genetic diversity of cacao pathogen Moniliophthora roreri in the upper Magdalena Valley of Colombia and its clonality
}

\section{OPEN ACCESS}

Edited by:

Helio K. Takahashi,

Universidade Federal de São Paulo,

Brazil

Reviewed by:

Luciana Lopes Guimaraes,

Universidade Santa Cecilia, Brazil

Anderson Messias Rodrigues,

Federal University of São Paulo, Brazil

${ }^{*}$ Correspondence:

Bryan A. Bailey,

Sustainable Perennial Crops Laboratory, Plant Sciences Institute,

United States Department of Agriculture/Agricultural Research

Service, Beltsville Agricultural Research Center-West, Beltsville, MD 20705, USA

bryan.bailey@ars.usda.gov

Specialty section: This article was submitted to Fungi and Their Interactions,

a section of the journal

Frontiers in Microbiology

Received: 26 June 2015 Accepted: 04 August 2015

Published: 27 August 2015

Citation:

Ali SS, Shao J, Strem MD,

Phillips-Mora W, Zhang D,

Meinhardt LW and Bailey BA (2015) Combination of RNAseq and SNP nanofluidic array reveals the center of genetic diversity of cacao pathogen Moniliophthora roreri in the upper Magdalena Valley of Colombia and its clonality. Front. Microbiol. 6:850. doi: 10.3389/fmicb.2015.00850

\begin{abstract}
Shahin S. Ali', Jonathan Shao', Mary D. Strem ${ }^{1}$, Wilberth Phillips-Mora², Dapeng Zhang ${ }^{1}$, Lyndel W. Meinhardt ${ }^{1}$ and Bryan A. Bailey ${ }^{1 *}$
\end{abstract}

\begin{abstract}
1 Sustainable Perennial Crops Laboratory, Plant Sciences Institute, United States Department of Agriculture/Agricultural Research Service, Beltsville Agricultural Research Center-West, Beltsville, MD, USA, ${ }^{2}$ Departamento de Agricultura y Agroforestería, Centro Agronómico Tropica de Investigación y Enseñanza, Turrialba, Costa Rica
\end{abstract}

Moniliophthora roreri is the fungal pathogen that causes frosty pod rot (FPR) disease of Theobroma cacao L., the source of chocolate. FPR occurs in most of the cacao producing countries in the Western Hemisphere, causing yield losses up to $80 \%$. Genetic diversity within the FPR pathogen population may allow the population to adapt to changing environmental conditions and adapt to enhanced resistance in the host plant. The present study developed single nucleotide polymorphism (SNP) markers from RNASeq results for $13 \mathrm{M}$. roreri isolates and validated the markers for their ability to reveal genetic diversity in an international $M$. roreri collection. The SNP resources reported herein represent the first study of RNA sequencing (RNASeq)-derived SNP validation in $M$. roreri and demonstrates the utility of RNASeq as an approach for de novo SNP identification in M. roreri. A total of 88 polymorphic SNPs were used to evaluate the genetic diversity of $172 \mathrm{M}$. roreri cacao isolates resulting in 37 distinct genotypes (including 14 synonymous groups). Absence of heterozygosity for the 88 SNP markers indicates reproduction in $M$. roreri is clonal and likely due to a homothallic life style. The upper Magdalena Valley of Colombia showed the highest levels of genetic diversity with 20 distinct genotypes of which 13 were limited to this region, and indicates this region as the possible center of origin for $M$. roreri.

Keywords: RNAseq, SNP, monilia pod rot, genotyping, biodiversity, homothallism

\section{Introduction}

Moniliophthora roreri $\mathrm{H}$. C. Evans, Stalpers, Samson, and Benny is the causal agent of frosty pod rot (FPR) of Theobroma cacao L. (Evans et al., 1978), a major cash crop in the tropics and the source of chocolate. FPR occurs in most major cacao producing countries in the Western Hemisphere, other than Brazil (Phillips-Mora et al., 2007a), causing yield losses up to $80 \%$ (Hidalgo et al., 2003). M. roreri is a hemibiotrophic fungus. During the biotrophic phase the fungus slowly colonizes the 
fruit causing malformations and positions itself to exploit the nutritive resources released when necrosis is triggered. A major shift in M. roreri gene expression occurs between the biotrophic and necrotrophic phases, and pod metabolites are rapidly metabolized by the pathogen during the necrotrophic phase and finally sporulation occurs (Bailey et al., 2013). Dikaryotization of the fungal mycelia from a haploid state is thought to occur in association with the shift to the necrotrophic phase.

As chemical control of FPR is not generally economically feasible (Bateman et al., 2005), an integrated disease management approach involving better agronomic practices combined with improved planting materials and possibly biological control approaches (Krauss and Soberanis, 2001; Krauss et al., 2010; de la Cruz et al., 2011), is the only feasible strategy for managing FPR at this moment. Though there are no cacao clones immune to $M$. roreri, highly tolerant clones have been developed by CATIE in Costa Rica (Phillips-Mora et al., 2005; Phillips-Mora, 2010). In addition, cacao clones like EET 233 and ICS 95 have demonstrated tolerance against FPR in screening studies conducted in Ecuador and Peru (Evans, 1981; Evans et al., 1998). Tolerance against $M$. roreri includes the induction of cacao defense responsive genes early in the infection process compared to that observed in susceptible clones (Ali et al., 2014). Losses to FPR in most CATIE selected tolerant clones has slowly increased over the past 15 years (Phillips-Mora et al., 2012) raising questions that the pathogen may be in the process of overcoming or "breaking" the tolerance. The pathogen has the potential to employ an intricate pattern of alternative gene expression when sucessfully causing disease in tolerant cacao clones (Bailey et al., 2014).

Though Ecuador was traditionally considered as the origin of FPR, recent reports have shown a higher genetic diversity in Colombia, which would make Colombia the true center of origin of M. roreri on cacao (Phillips-Mora et al., 2007a). Until the 1970s, FPR was confined to Colombia, Ecuador, western Venezuela and eastern Panama (Phillips-Mora et al., 2007b) and was regarded as a geographically isolated pathogen (Holliday, 1971). It then moved northward into Central America through Panama and reached Costa Rica in the late 1970s (Enríquez and Suarez, 1978), where production fell fivefold due to FPR (Hidalgo et al., 2003). FPR has continued to spread northward, with its presence being confirmed in Guatemala, Honduras, and Mexico (Phillips-Mora et al., 2006, 2007a,b). The spread of the disease into Central America may have been by airborne spores; however, movement as a result of human activities is considered more likely (Orellana, 1956). On the other hand, the natural dispersion of the FPR disease from western Ecuador to areas further south and east was limited by the Andes, an impassable barrier that limited the spread of the disease until the 1980s (Evans, 1986). The introduction of the FPR disease into the Amazonian regions of Eastern Ecuador coincided with new agricultural development, the construction of oil pipelines and roads into the Eastern Ecuador. From there, the pathogen dispersed southward along the eastern slopes of the Andes reaching first Peru (Hernández et al., 1990) and, more recently, Bolivia (Phillips-Mora et al., 2012).
Genetic diversity within the population of a fungal pathogen allows specific individuals in the population to adapt to changing environmental conditions, particularly to enhanced resistance or tolerance of the host, which is developed by natural selective pressures or introduced by plant breeders (Wang and Szmidt, 2000; Carlile et al., 2001). Therefore a proper understanding of the genetic variation in this plant pathogen is critical to the establishment of an effective and sustainable resistance breeding program. Amplified fragment length polymorphisms (AFLP) and inter simple sequence repeat (ISSR) marker analysis showed that M. roreri has five genetic groups (Phillips-Mora et al., 2007a), the two major ones being the Bolivar group, comprising isolates from Colombia, Peru, Venezuelan, and Ecuador and the Co-West group, comprising isolates from Colombia, Ecuador, and Central America. The other three groups are endemic to Colombia and North-Western Ecuador. The recent designation of North-Western Colombia as the center of diversity and origin of FPR (Phillips-Mora et al., 2007a) makes it especially important to examine, the genetic diversity of the pathogen in this region in depth. This knowledge is necessary when establishing and maintaining breeding programs for disease tolerance and in developing and deploying integrated disease management strategies that include the planting of tolerant cacao clones.

Although ISSR and AFLP markers are useful in assessing genetic diversity, it is important for long term studies to develop co-dominant molecular markers that can accurately identify each individual isolate and give more consistent quantitative results. Single nucleotide polymorphisms (SNPs) represent the most copious source of genetic variation and are linked to heritable differences between individual strains of a pathogen (Suh and Vijg, 2005). Since the $M$. roreri genome was recently sequenced using an Ecuadorian isolate (Meinhardt et al., 2014), discovering SNPs by comparison of NGS data with the genomes or ESTs could be an effective tool. Exome sequencing (Ng et al., 2009) is based on the hypothetical foundation that the majority of pathogenicity related mutations are located within coding sequences. Though RNA sequencing (RNASeq) is mainly considered a method of gene expression analysis, it is also a form of exome sequencing with the capacity to detect SNPs in the genes that are expressed (Quinn et al., 2013). SNP detection using RNASeq results has been validated in many studies (Chepelev et al., 2009; Cánovas et al., 2010; Salem et al., 2012; Vidal et al., 2012).

The objectives of the present study were to develop SNP markers through the data mining and comparison of RNASeq results from $13 \mathrm{M}$. roreri isolates and the reference genome sequence (Meinhardt et al., 2014) and access these SNP markers for their ability to reveal genetic diversity in an international $M$. roreri culture collection. The SNP resources reported herein represent the first study of RNASeq based SNP discovery and validation in $M$. roreri, demonstrating the utility of RNASeq results as an approach for de novo SNP identification in this pathogen. These SNP markers, as well as the genotyping method developed, will allow researchers to address key questions about the population genetics of $M$. roreri. For example SNP analysis could help us understand: recombination events, fungal mating types, pathogen genetics, and population adaptations resulting from changes in the host genetics, and help predict the stability of 
new tolerant host plants developed by plant breeding programs. In this study, we identify and characterized 88 SNP markers in $M$. roreri and use them to assess the genetic diversity of $M$. roreri across its geographic range.

\section{Materials and Methods}

\section{Moniliophthora roreri Isolates}

Most isolates used in this study belong to CATIE's collection of $M$. roreri collected from affected areas of South and Central America from 1999 to 2013 (See Supplementary Excel file S1). All samples were obtained from infected fruits of T. cacao. A significant percentage of all isolates were collected from Colombia, since Colombia is now presumed to be the center of origin of the pathogen (Phillips-Mora et al., 2007a). A considerable representation of isolates were also obtained from Costa Rica since that is where the CATIE breeding program resides and to compare changes in genetic diversity of the fungus post dispersal from the presumed center of origin. Two additional $M$. rorer $i$ isolates were obtained from the ATCC (ATCC42952 and ATCC64239) that were isolated in 1978 and 1984, respectively, from Costa Rica. M. roreri cultures were isolated from pods showing the initial or intermediate stages of external necrosis. Pods were cut with a sterile knife and small internal tissue sections from the zone where necrotic and healthy tissues meet were removed to water agar plates. Cultures typical of $M$. roreri, slow growing white mycelia, were transferred to V8 medium $(20 \% \mathrm{w} / \mathrm{v}$ V8 juice, $0 \cdot 1 \% \mathrm{w} / \mathrm{v}$ asparagine, $2 \cdot 0 \% \mathrm{w} / \mathrm{v}$ maltose, $1 \cdot 8 \%$ $\mathrm{w} / \mathrm{v}$ agar). Isolates were shipped to USDA-APHIS-PPQ facility in Beltsville, MD and transferred to USDA-ARS Sustainable Perennial Crops Lab in Beltsville, MD after inspection.

\section{DNA and RNA Extraction}

For DNA extraction, 2-3 agar plugs $\left(0.25 \mathrm{~cm}^{2}\right)$ were transferred from cultures grown on V8 media to $50 \mathrm{ml}$ falcon tubes containing $20 \mathrm{ml}$ liquid clarified V8 media (Drenth and Sendall, 2001) and grown at room temperature while shaking at $100 \mathrm{rpm}$. Cultures were allowed to grow for 15-20 days. Mycelia were washed with sterile water and collected by centrifuging at $20,000 \mathrm{~g}$ for $10 \mathrm{~min}$ in the same falcon tube followed by flash freezing in liquid nitrogen and freeze drying. Genomic DNA was extracted as mentioned by Ali et al. (2014).

For RNA extraction, 2-3 agar plugs were transferred from cultures grown on V8 agar plate to $250 \mathrm{ml}$ conical flask containing $50 \mathrm{ml}$ potato dextrose broth and grown at room temperature $\left(22-25^{\circ} \mathrm{C}\right)$ while shaking at $100 \mathrm{rpm}$. Cultures were allowed to grow for 10-15 days. Mycelia were washed with sterile water and collected by centrifuging at 20,000 $\mathrm{g}$ for $10 \mathrm{~min}$ followed by flash freezing in liquid nitrogen and freeze drying. Freeze-dried mycelia were ground in a mortar and pestle in liquid nitrogen and transferred to a $50 \mathrm{~mL}$ centrifuge tube containing $15 \mathrm{~mL}$ of $65^{\circ} \mathrm{C}$ extraction buffer (Bailey et al., 2005). Additional extraction methods were conducted as in Bailey et al. (2013). Using a NanoDrop spectrophotometer (Thermo Scientific, Wilmington, DE, USA), RNA and DNA concentrations were determined by absorbance at $260 \mathrm{~nm}$ and purity was estimated by the $260 / 280$ ratio and the $260 / 230$ ratio.

\section{RNASeq Analysis and Mining of Putative SNPs}

RNA Sequencing analysis was carried out by the National Center for Genome Resources (Santa Fe, NM, USA). For the RNASeq analysis, cDNA was generated using a routine RNA library preparation TruSeq protocol developed by Illumina Technologies (San Diego, CA, USA). Using the kit, mRNA was first isolated from total RNA by performing polyA selection step, followed by construction of single end sequencing libraries with an insert size of $160 \mathrm{bp}$. Single-end sequencing was performed on 13 samples using the Illumina HiSeq platform. Samples were multiplexed with unique six-mer barcodes generating 627,844,665 filtered (for Illumina adapters/primers, and PhiX contamination) $1 \times 50 \mathrm{bp}$ read pairs. Each library (Co17, Co7, E18, Co15, E16, E43, C13, Co12, Co8, Co11, E32, P1, and MCA2977) ranging from 20 to 62 million reads in fastq format was aligned to the $M$. roreri (MCA2977) genome sequences (Meinhardt et al., 2014) using a memory-efficient short-read aligner Bowtie-0.12.7 (Langmead et al., 2009). The files were outputted into SAM (Sequence Alignment/Map) format. The files were converted to BAM format, a binary format for storing sequence data and sorted using SAMtools (Li et al., 2009). Variant calling was performed using SAMtools mpileup and bcftools with default parameters, which generated a VCF file (variant call format; Li et al., 2009). The resulting VCF file was filtered manually using Excel functions. All SNPs with QUAL $<999$ and DP $<30$ were removed (Danecek et al., 2011). SNPs were further filtered based on genotype quality (GQ) and a homozygous alternate $(1 / 1)$ or heterozygous (0/1) SNP call was retained if there was at least one library supporting it (GQ $\geq 40$; See Supplementary Excel file S2). SNPs were further verified and manually visualized using the bioinformatics suite DNASTAR using the program SeqMan Pro (DNASTAR, 1999). In order to meet the requirements and constraints for primer design, all candidates for SNP markers with less than 80 nucleotides between two neighboring SNPs, and with flanking sequences less than 100 nucleotides long, were removed. The overview of the SNP mining strategy has been presented in Figure 1. A subset of the identified SNP flanking sequences was then chosen for design and synthesis of primers to assay for SNPs (See Supplementary Excel file S2).

\section{Confirmation of In Silico SNPs}

To confirm that the in silico generated SNPs are not due to paralogous genes, we randomly selected 25 putative homozygous and heterozygous SNPs and performed BLASTn searches of the $\sim 100$ bp flaking regions against the $M$. roreri MCA 2997 (taxid:221103) whole-genome shotgun contigs. As the homozygous SNPs showed single hits while the heterozygous SNPs showed multiple hits within the $M$. roreri genome (See Supplementary Excel file S3), one homozygous and four heterozygous SNPs were further confirmed by Sanger sequencing. The PCR-amplified products flanking putative homozygous and heterozygous SNP markers from different $M$. roreri isolates were recovered from agarose gels and purified using QIAGEN gel purification kits (QIAGEN, Dusseldorf, 
Alignment of the 13 RNASeq libraries with the $M$. roreri genome using shortread aligner Bowtie-0.12.71.

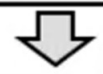

Variant calling using SAMtools mpileup and bcftools ${ }^{2}$.

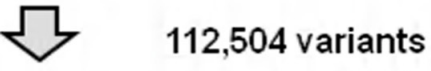

Removed variants with QUAL $<999$ and $\mathrm{DP}<30$.

ॠ 31,948 variants

Retain homozygous alternate and heterozygous variants if at least one library supported it ( $G Q \geq 40)$.

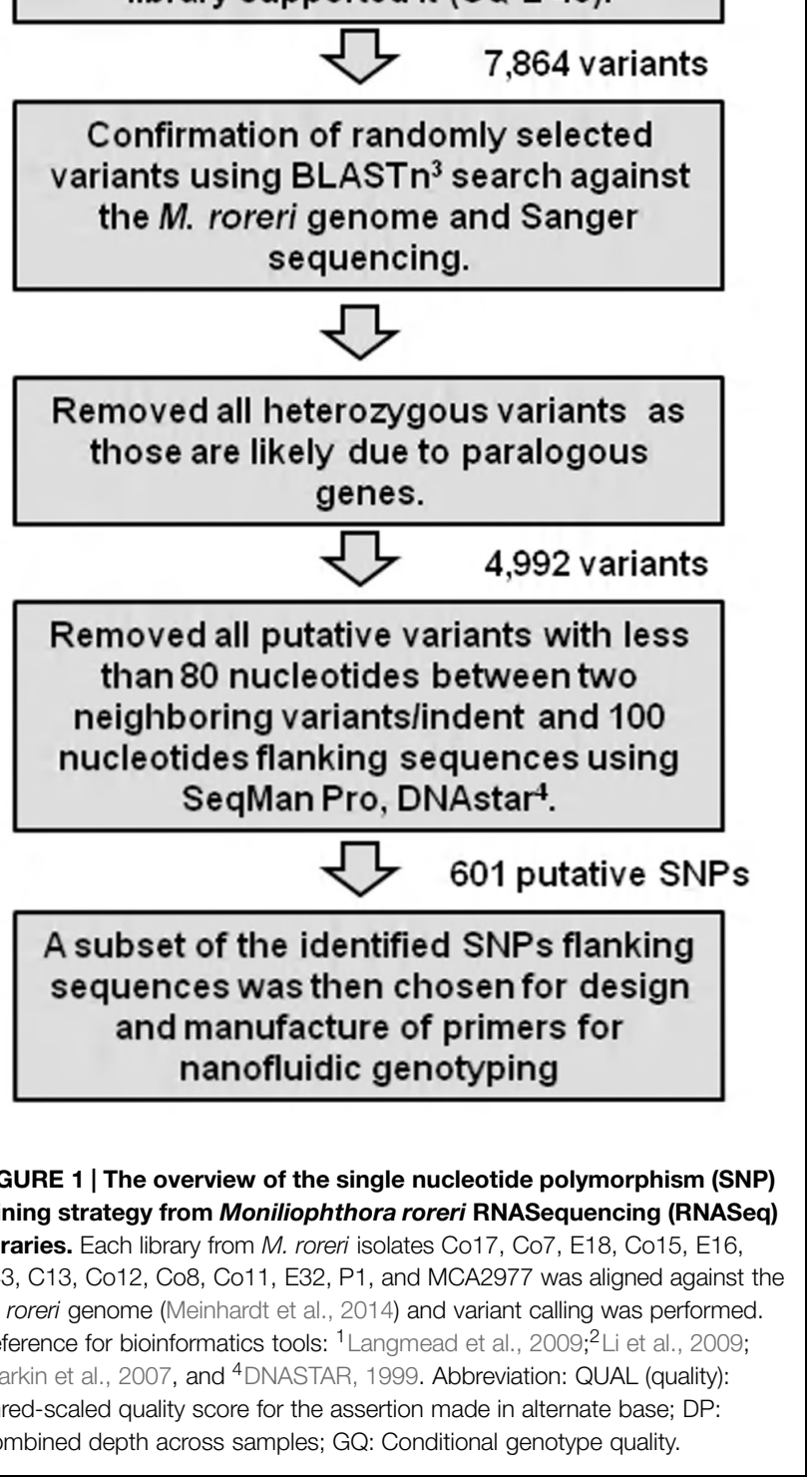

Germany; See Supplementary Table S1 for primers used for PCR amplifications). The purified amplicons were cloned into pCR4TOPO vector (TOPO TA Cloning Kit, Life Technologies, USA) and transformed in to DH5-alpha Escherichia Coli (New England Biolab, USA) according to the manufacturers protocol. Then 912 clones from each amplicon were randomly selected to be commercially sequenced (Macrogen, Rockville, MD, USA) from both ends using M13F and M13R primers. After removing the vector sequences, ClustalW2 (Larkin et al., 2007) was used to compare the DNA sequences of each clones and the original sequences containing the SNP.

\section{Design of the SNP Panel and Validation of Putative SNPs}

To evaluate the putative SNP markers for suitability of genotyping the $M$. roreri isolates, a nanofluidic genotyping system was used to validate the SNPs for 172 samples (See Supplementary Excel file S1). A total of 288 SNP sequences were submitted to the Assay Design Group at Fluidigm Corporation (South San Francisco, CA, USA) for design and manufacture of primers for a SNPtype ${ }^{\mathrm{TM}}$ genotyping panel. The assays were based on competitive allele-specific PCR and enable bi-allelic scoring of SNPs at specific loci (KBioscience Ltd., Hoddesdon, UK). The Fluidigm SNPtype ${ }^{\mathrm{TM}}$ Genotyping Reagent Kit was used according to the manufacturer's instructions. Using these primers, the isolated DNAs were subjected to Specific Target Amplification (STA) in order to enrich the SNP sequences of interest. Genotyping was performed on a nanofluidic 96.96 Dynamic Array IFC (Integrated Fluidic Circuit; Fluidigm Corp., South San Francisco, CA, USA). This chip automatically assembles PCR reactions, enabling simultaneous testing of up to 94 samples with 96 SNP markers. The use of a 96.96 Dynamic Array ${ }^{\mathrm{TM}}$ IFC for SNP genotyping of human samples was as described by Wang et al. (2009). End-point fluorescent images of the 96.96 IFC were captured and processed with an $\mathrm{EP}^{\mathrm{TM}}$ imager (Fluidigm Corp., CA, USA). The data was analyzed with Fluidigm Genotyping Analysis Software (Fluidigm SNP genotyping user guide, Fluidigm, South San Francisco, CA, USA).

\section{Validation of Heterozygous SNP Calls by the Fluidigm System}

To validate the heterozygous SNP calls by the Fluidigm system, two such putative SNPs were tested for three $M$. roreri isolates using Sanger sequencing. The PCR-amplified products flanking putative SNP markers from different $M$. roreri isolates were recovered from agarose gels and purified using QIAGEN gel purification kits (QIAGEN, Dusseldorf, Germany; See Supplementary Table S1 for primers used for PCR amplifications). The purified amplicons were cloned into pCR4TOPO vector (TOPO TA Cloning Kit, Life Technologies, USA) and transformed in to DH5-alpha E. Coli (New England Biolab, USA) according to the manufacturers protocol. Then 9-12 clones from each amplicon were randomly selected to be commercially sequenced (Macrogen, Rockville, MD, USA) from both ends using M13F and M13R primers. After removing the vector sequences, ClustalW2 (Larkin et al., 2007) was used to compare 
the DNA sequences of each clones and the original sequences containing the SNP.

\section{Data Analysis}

For genotype identification, pair-wise multilocus matching was applied among individual samples using the program GenAlEx 6.5 (Peakall and Smouse, 2006, 2012). DNA samples that were fully matched at the genotyped SNP loci were declared the same genotype (or clones). Distance-based multivariate analysis was used to assess the relationship among the individual isolates. Pair-wise genetic distances as defined by Peakall et al. (1995) were computed using the DISTANCE procedure implemented in GenAlEx 6.5. The same program was then used to perform Principal Coordinates Analysis (PCoA), based on the pair-wise distance matrix. Both distance and covariance were standardized. Cluster analysis was used to further examine the genetic relationship among isolates. Nei et al.'s (1983) genetic distance was calculated using Microsatellite Analyzer (MSA; Dieringer and Schlötterer, 2003) and 100 bootstrap replications were applied. A consensus dendrogram was generated from the resulting distance matrix using the neighbor-joinig algorithm (Saitou and Nei, 1987) available in PHYLIP (Plotree and Plotgram, 1989), and visualized using Figtree ver. 1.3.1 (Rambaut, 2009).

\section{Results}

\section{RNASeq Analysis and SNP Discovery}

The number of quality RNA reads ( $>50 \mathrm{bp}$ ) from RNASeq libraries ranged from 20 to 62 million reads (Table 1). After aligning the reads against the $M$. roreri reference genome sequence (Meinhardt et al., 2014) variant calling generated 112,504 putative SNPs in 2,350 M. roreri reference genome contigs. After filtering the SNPs as mentioned in the methods, a total of 7,862 putative CDS (coding DNA sequence)-based SNPs were obtained (See Supplementary Excel file S2). There were 6,329 transition type SNPs, including 3,191 C/T and 3,138 A/G; while there were 1,497 transversion type SNPs, including $283 \mathrm{~A} / \mathrm{T}, 427 \mathrm{~A} / \mathrm{C}, 390 \mathrm{~T} / \mathrm{G}, 397 \mathrm{C} / \mathrm{G}$, and 36 triallelic polymorphisms. Among the $12 \mathrm{M}$. roreri libraries, the total number of putative SNPs (QUAL $\geq 999$, DP $\geq 30$, and $\mathrm{GQ} \geq 40$ ) ranged between 224 and 2,340 (Table 1). The ratios between homozygous and heterozygous SNPs ranged between 1.9 and 0.1 (Table 1). Among the 25 randomly selected homozygous and heterozygous SNPs tested, none of the homozygous SNPs containing flanking regions showed more than one hit $(E>2 e-$ 50) within the $M$. roreri genome while all but one heterozygous SNP containing flanking regions showed two or more hits $(E>2 e-50)$ with the exception being SNP 485_1_1286 (See Supplementary Excel file S3). This obviously raised a question concerning the validity of heterozygous SNP calls necessitating the validation of heterozygous SNPs by Sanger sequencing.

Sanger sequencing of PCR-amplicons containing a putative homozygous SNP from three $M$. roreri isolates validated the presence of that homozygous SNP (See Supplementary Figure S1). On the other hand Sanger sequencing of PCR-amplicons containing four putative heterozygous SNPs for M. roreri isolate C13 showed that there was no actual heterozygosity (See Supplementary Figure S2). Beside SNP 058_2_8046, the other three SNPs can be explained as misalignment between two or more paralogous genes. Though the SNP 485_1_1286 flanking region showed no paralogous genes during the initial BLASTn search of the genome, Sanger sequencing indicated the presence of two paralogous genes. As we continuously extended the sequence reads out from SNP 485_1_1286 we reached a point where there was no sequence homology and the SNP was invalidated (Figure 2). Therefore we selected 288 homozygous SNPs for validation by genotyping a test panel of $172 \mathrm{M}$. roreri isolates from the most important FPR affected areas of South and

TABLE 1 | List of RNASequencing (RNASeq) libraries.

\begin{tabular}{|c|c|c|c|c|c|}
\hline \multirow[t]{2}{*}{$\begin{array}{l}\text { Moniliophthora } \\
\text { roreri isolates }\end{array}$} & \multirow[t]{2}{*}{ Origin } & \multirow[t]{2}{*}{ Genetic group $\#$} & \multirow[t]{2}{*}{$\begin{array}{l}\text { No. of RNA reads } \\
\text { in each library }\end{array}$} & \multicolumn{2}{|c|}{$\begin{array}{l}\text { No. of single nucleotide polymorphisms } \\
(Q U A L \geq 999, D P \geq 30, \text { and } G Q \geq 40 \text { ) }\end{array}$} \\
\hline & & & & Homozygous & Heterozygous \\
\hline $\mathrm{C} 13$ & Costa Rica & IV, Co-West & $51,121,595$ & 948 & 807 \\
\hline Co12 & Colombia & II, Co-Central & $20,354,728$ & 1539 & 801 \\
\hline Co8 & Colombia & IV, Co-West & $51,581,527$ & 348 & 381 \\
\hline Co15 & Colombia & III, Co-East & $50,369,121$ & 463 & 516 \\
\hline Co11 & Colombia & II, Co-Central & $50,921,967$ & 283 & 477 \\
\hline Co17 & Colombia & II, Co-Central & $49,462,215$ & 258 & 371 \\
\hline $\mathrm{Co} 7$ & Colombia & II, Co-Central & $49,467,859$ & 458 & 276 \\
\hline E16 & Ecuador & IV, Co-West & $52,294,090$ & 377 & 548 \\
\hline E18 & Ecuador & IV, Co-West & $44,491,879$ & 262 & 428 \\
\hline E32 & Ecuador & V, Boliver & $62,268,785$ & 436 & 578 \\
\hline E43 & Ecuador & I, Gileri & $52,827,877$ & 804 & 531 \\
\hline P1 & Peru & V, Boliver & $44,820,900$ & 24 & 218 \\
\hline MCA2977 & Ecuador & Not known & $47,862,122$ & 41 & 306 \\
\hline
\end{tabular}

\#As described by Phillips-Mora et al. (2007a). 


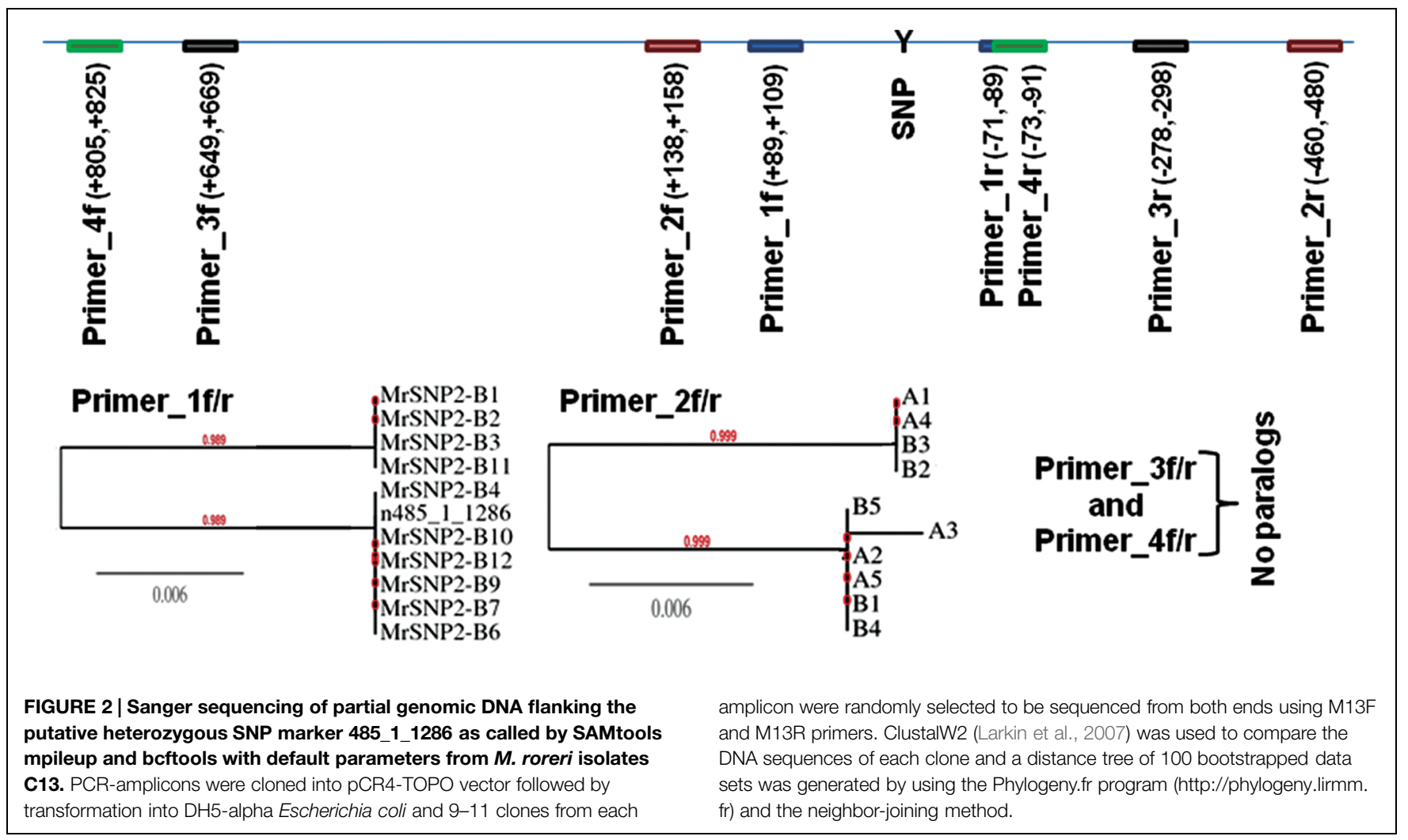

Central America. The overview of the SNP mining strategy from $M$. roreri RNASeq libraries shows the stringency involved at the various levels (Figure 1).

\section{Frequency of SNP Markers and Descriptive Statistics}

Out of the chosen 288 SNP markers, 232 primer sets were successful in specific targeted amplification. The failure of the remaining 56 primer sets was likely due to the sequence complexity or the presence of polymorphisms within the flanking sequences. Though all the SNPs tested here were homozygous based on the in silico variant calling, Fluidigm genotyping analysis software called 69 SNPs as heterozygous. To validate the heterozygous SNP calls by the Fluidigm system, two such putative SNPs were tested from three $M$. roreri isolates using Sanger sequencing. Sanger sequencing invalidated the presence of heterozygosity (See Supplementary Figure S3). We further discarded the SNPs that were monomorphic or didn't show consistent allelic intensity between two replicating experiments. A total of 88 polymorphic SNPs were retained for further analysis (See Supplementary Excel files S1 and S4). These 88 SNPs were reliably scored across the validation panel and thus, were considered true SNPs. The minor allele frequency of these SNPs ranged from 0.01 to 0.483 with an average of 0.218 . There was no heterozygosity observed among any of the 88 SNP markers except in a very few instances which we attributed to the Fluidigm genotyping analysis software error, which was later established by Sanger sequencing. All these 88 SNPs can be repeated in genotyping to obtain fully identifiable genotypes.

\section{Genetic Relationship among M. roreri Isolates}

The genetic relationships among the $172 \mathrm{M}$. roreri isolates are presented in a PCoA plot (Figure 3A). Based on the PCoA results and aligning all the isolates according to the SNPs (See Supplementary Excel file S1), we can conclude that there are 37 groups of distinct SNP patterns and all the isolates within a group are synonymous (Syn Grp.). Among these 37 distinct genotypes (14 Syn Grp. and 23 isolates with unique genotypes), 36 were present in Colombia followed by four in Ecuador (Table 2). All 86 Costa Rican isolates along with two Colombian and one Ecuadorian isolates were synonymous (Syn Grp. 1). While all the Bolivian and Peruvian isolates along with one Ecuadorian isolate formed another synonymous group (Syn Grp. 2). Treating each synonymous group as an individual isolate allows all of the 37 distinct genotypes to be grouped into two major clusters. One comprised most of the variant Colombian isolates along with two Ecuadorian isolates (E-06, and E-07), while the other cluster is mostly comprised of the synonymous groups derived from Costa Rican, Colombian, Venezuelan, Bolivian, and Ecuadorian isolates (Figure 3A).

A dendrogram was generated based on the SNP profiles for the synonymous groups and isolates with unique genotypes. This analysis increased the resolution and the degree of statistical support for the groups identified, with two discrete phylogenetic groups of isolates ( $a$ and $b$ ) supported by bootstrap values $>50 \%$, and another four phylogenetic sub-groups that were poorly supported, which were derived from Colombia isolates (Figure 3B). Approximate geographical locations for all of the 172 isolates are shown in Figure 4. 


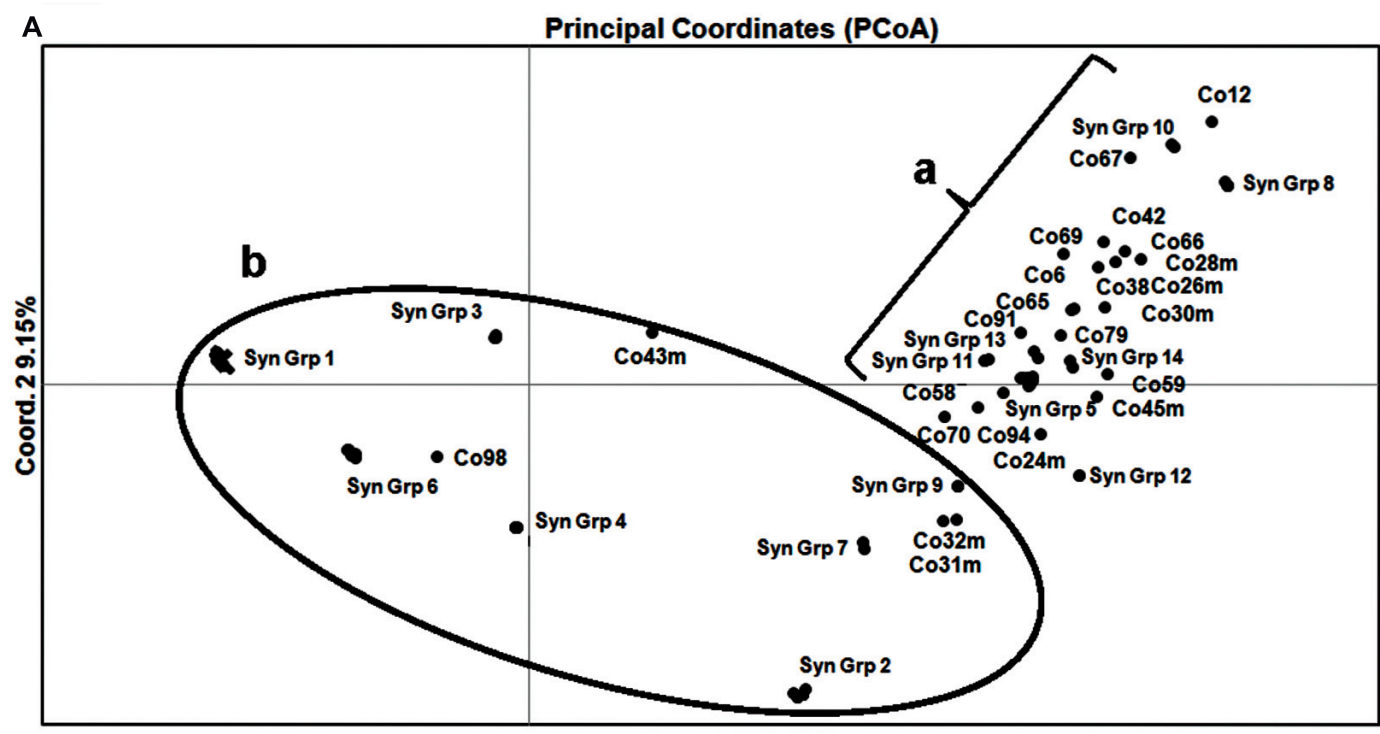

Coord. $159.48 \%$

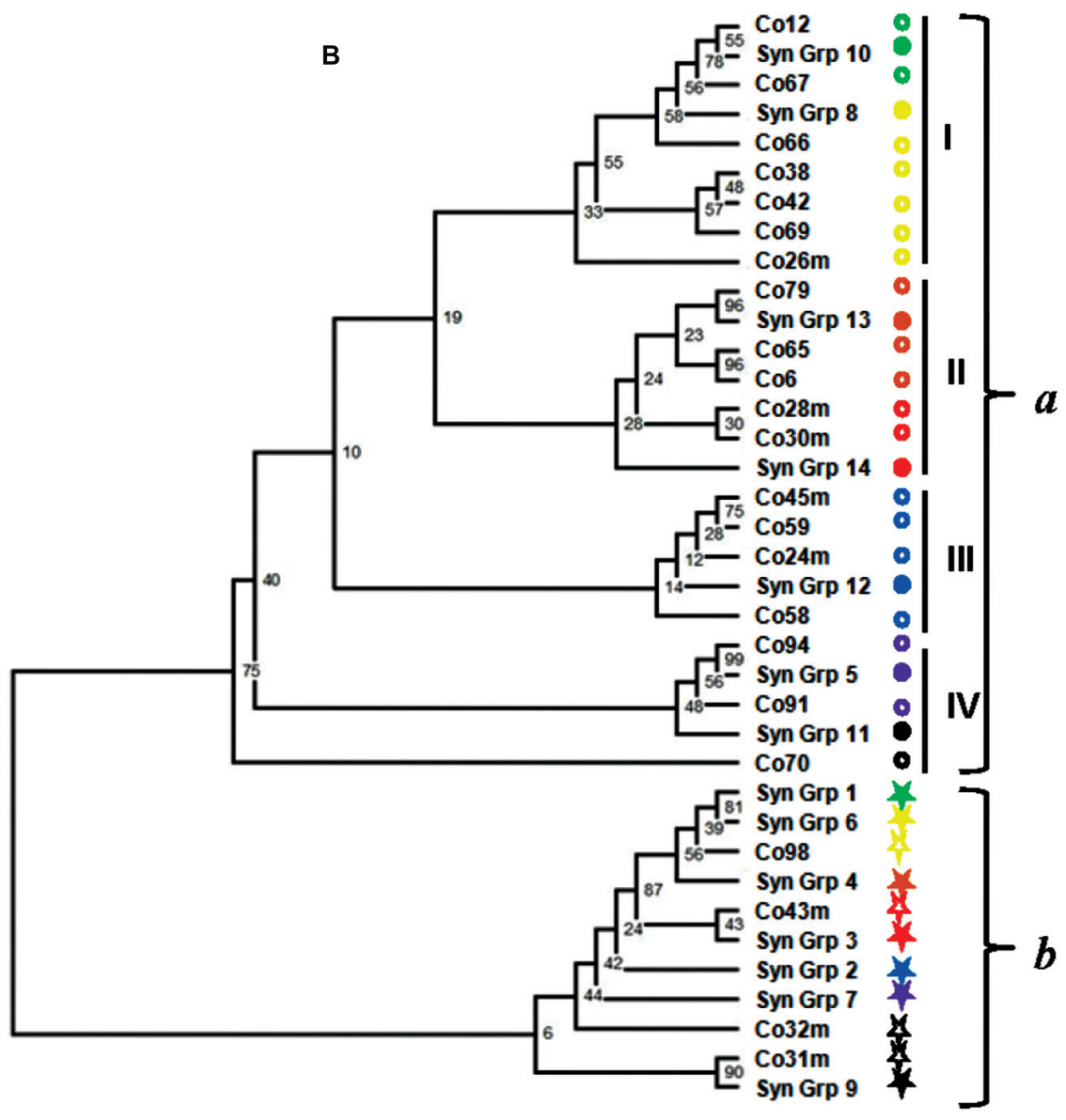

FIGURE 3 | Genetic relationships based on 88 SNP markers among $172 \mathrm{M}$. roreri isolates collected from frosty pod rot affected areas of South and Central America. (A) Principal Coordinates Analysis based on the pairwise distance matrix. The plane of the first three main PCO axes accounted for $75.1 \%$ of total variation. First axis $=59.48 \%$ of total information, the second $=9.15 \%$, and the third $=6.47 \%$. (B) Cluster analysis and a consensus dendrogram were generated from the resulting distance matrix using the neighbor-joining algorithm (Saitou and Nei, 1987) and visualized using Figtree ver. 1.3.1 (Rambaut, 2009). Nei et al.'s (1983) genetic distance was calculated using microsatellite analyzer (Dieringer and Schlötterer, 2003) and 100 bootstrap replications were applied. 
TABLE 2 | Geographic origin of 172 Moniliophthora roreri isolate.

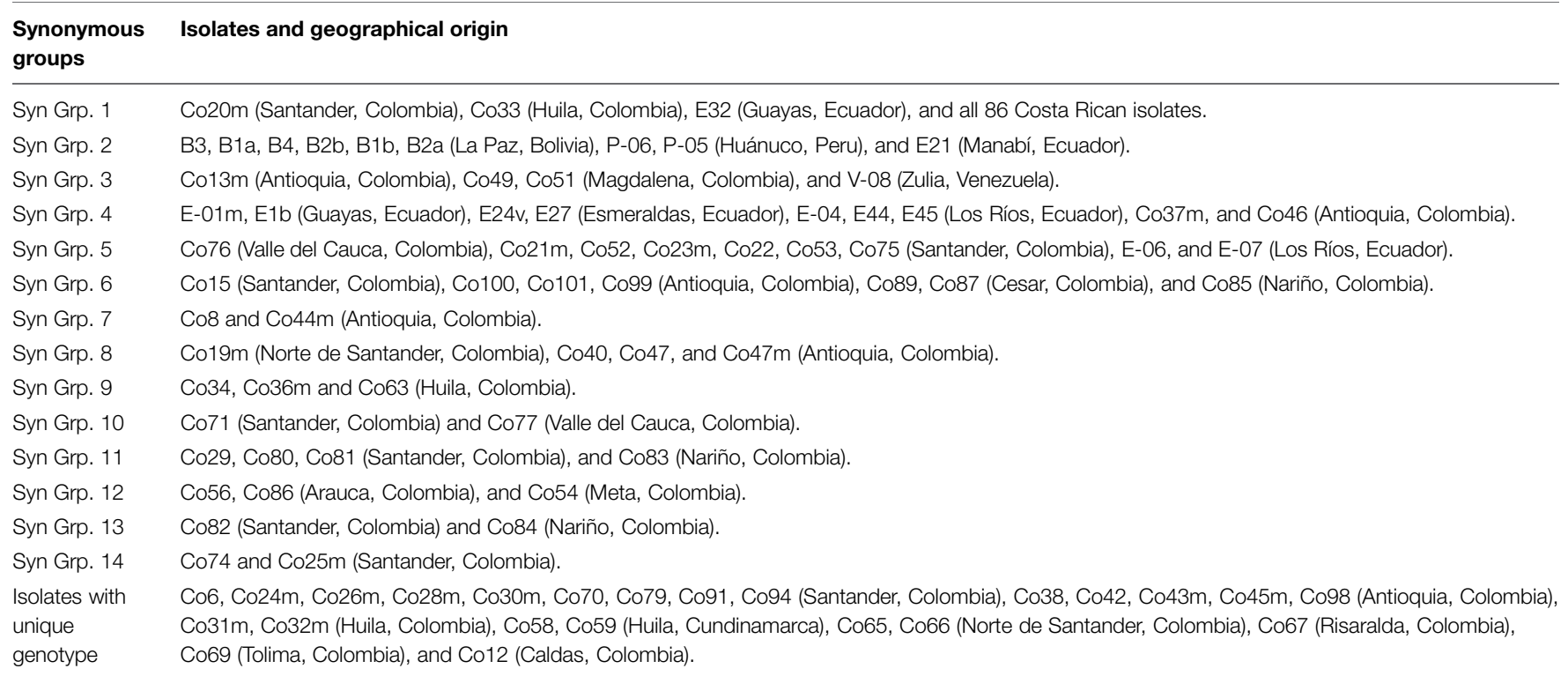

See Supplementary Excel file $S 1$ for further details.

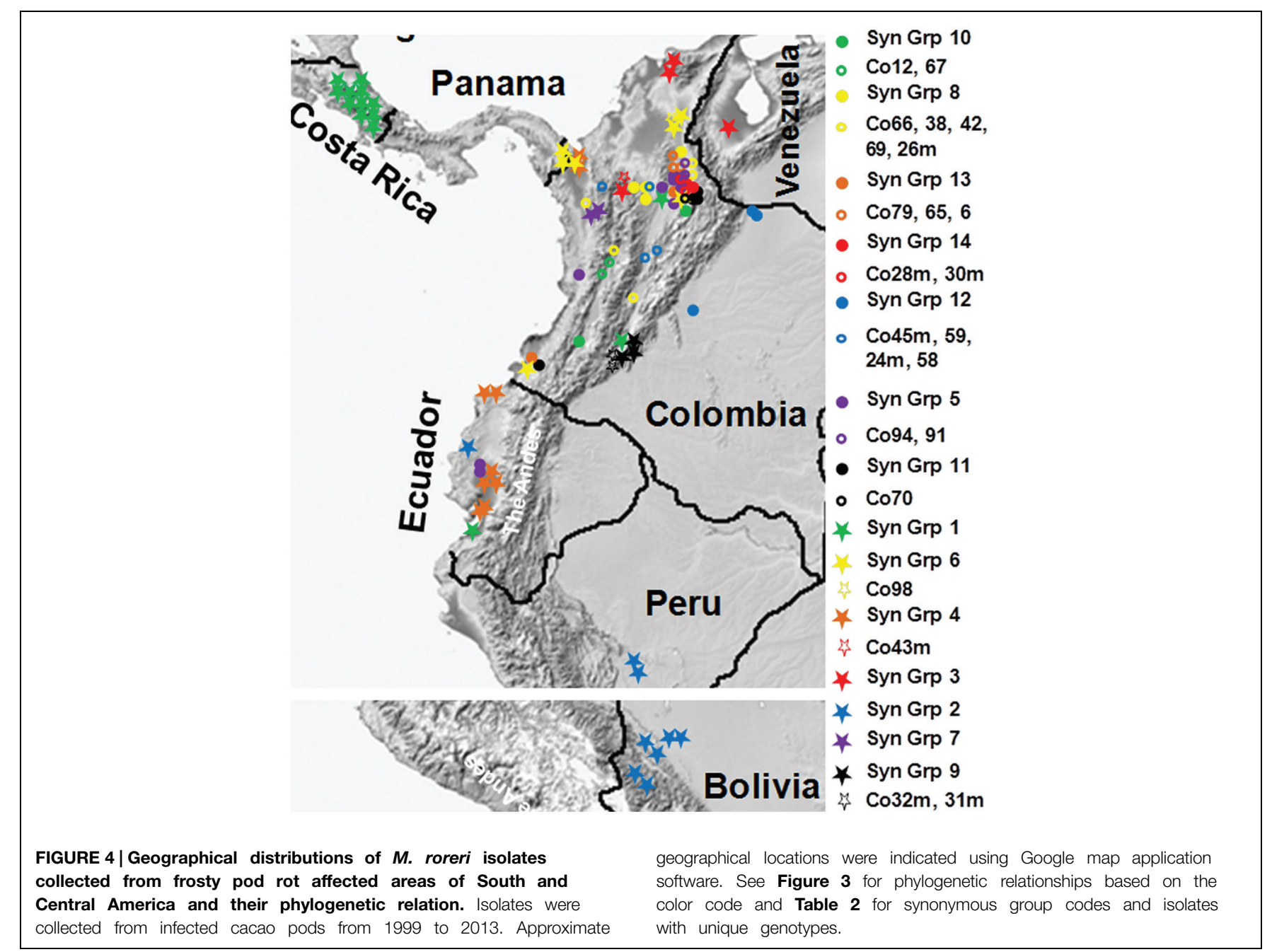




\section{Discussion}

Due to the insufficient throughput and data standardization issues over time and between research facilities, the existing molecular marker-based genotyping technology for M. roreri, such as AFLP and SSR markers, is of limited use and a more robust and quicker analytical marker system is needed. Although whole genome sequencing may have generated more SNPs, the present study demonstrates the usefulness of next-generation sequencing (NGS) of RNA as a method of SNP detection using expressed genes of $M$. roreri. The developed SNP panel has already proven to be a powerful tool for studying the dispersion, evolution and epidemiology of this pathosystem, and will have a major impact on future studies designed to understand the interplay between pathogen genetic diversity and host resistance/tolerance.

The $M$. roreri isolates included in the RNASeq analysis were selected to represent all five of the genetic groups previously reported by Phillips-Mora et al. (2007a). To have a similar transcript pool and avoid complex fractions of the total transcriptomes, all of the isolates were cultured in a simple media (PDB) prior to RNA isolation. BLASTn searches of the SNPflanking sequence for the 88 confirmed SNPs also didn't show any bias toward any particular type of coding sequence (See Supplementary Excel file S4). It was interesting to see that 25\% of the SNP containing transcripts had no homologies within the predicted CDS of the recently published $M$. roreri genome (Meinhardt et al., 2014). These new CDS were visible as viable transcripts based on sequence alignments implying that $M$. roreri has many more genes than previously thought.

The SNP discovery process for $M$. roreri was more difficult than anticipated. Only 88 of the putative SNPs identified by RNASeq analysis and selected for verification produced usable SNP markers. Though the process is considered to be robust, SNP discovery though NGS attempts have showed highly variable frequency of SNP validation, ranging from $48 \%$ in rainbow trout (Sánchez et al., 2009), 70\% in the coral (Meyer et al., 2009), 83\% in Eucalyptus (Novaes et al., 2008), and $85 \%$ in maize (Barbazuk et al., 2007). Moreover, the limited genetic variability observed among the $M$. roreri isolates studied herein may be one of the reasons for the restricted SNP validation. In general, the likely causes of erroneous SNP selection include sequencing errors, sample contamination from other species, biased sample pooling, and sequencing library construction (Tollenaere et al., 2012), and, as we have demonstrated, alignment of paralogs (Garvin et al., 2010). Because the SNP identification process was based on a comparison with the reference genome sequence MCA2977, it is logical, as observed, to expect very few homozygous SNPs with this isolate. But unlike other isolates, a high heterozygous to homozygous ratio (7.5) was obtained for $M$. roreri isolate MCA2977, which indicates the in silico heterozygosity might be a result of sequencing errors or more likely due to paralogous gene alignments as shown. Moreover $M$. roreri is thought to be sexually propagated through meiosis (Evans et al., 2002) in which case it should show both the homozygous and heterozygous SNP combinations for the same allele. But only seven such combinations were found among the 7,862 putative SNPs (See Supplementary Excel file S2). This further indicates that the heterozygosity we observed in the in silico results is not due to recombination but sequencing errors. In this case, we were able to verify alignment errors due to misalignments of reads between closely related genes and gene families. Indeed, when we visualized the SNPs using the bioinformatics suite SeqMan Pro of DNASTAR, a majority of the heterozygous SNPs resulted from misalignment of truncated reads ( $<50 \mathrm{bp}$ ) and/or were located within regions presenting additional flanking SNPs (data not shown). A BLASTn search against the $M$. roreri genome has further confirmed the postulation that the majority of these heterozygous SNPs are actually associated with misalignment between paralogous sequences instead of unique genes. Moreover, Sanger sequencing of partial genomic DNA fragments associated with specific SNPs has validated homozygous SNPs which vary between isolates but not heterozygous SNPs. Therefore we adopted a very stringent approach for the final SNP calling (Figure 1).

The present method of nanofluidic array of SNP markers can handle a large amount of samples in a short period of time and is highly robust and repeatable. The STA protocol (Wang et al., 2009) used in the study efficiently dealt with the quality or quantity of DNA extracted from the $M$. roreri isolates by performing a multiplex PCR reaction before genotyping, using primers for all loci of interest, but without targeting the specific alleles, thus proportionally increasing the copies of these loci. Results from the repeatedly genotyped isolates showed 100\% concordance of allelic intensity for the 88 selected SNPs, and suggests that the nanofluidic system is a reliable platform for generating $M$. roreri isolate genotypes with high accuracy. In the few instances where the Fluidigm genotyping analysis software erroneously called heterozygous SNPs, it was observed that the allelic intensity of the non-template controls (NTC) for those SNPs were comparatively high. Therefore it is necessary to stringently check the NTC values for any SNP panel using the Fluidigm system.

If $M$. roreri reproduces sexually with any frequency as predicted previously by Evans et al. (2002) and were heterothallic, we should have seen heterozygosity among the 88 homozygous SNP markers tested here within the large population from a close geographical area like Colombia. The absence of heterozygosity for 88 SNP markers within Colombia suggests that there is no recombination occurring among the $M$. roreri isolates and would seem to make it highly unlikely that $M$. roreri reproduces by sexual recombination with any significant frequency. PhillipsMora et al. (2007a) also observed very low recombination in $M$. roreri population analysis using AFLPs and ISSRs suggesting $M$. roreri reproduction is clonal. The present study confirms in unambiguous terms that $M$. roreri reproduction is clonal but does not rule out meiosis as a common occurrence in $M$. roreri.

During the biotrophic phase of $M$. roreri infection, the fruit develops malformations and then progresses to the necrotrophic phase where rot occurs, followed by sporulation on the pod surface (Evans et al., 2002; Evans, 2007). The spores are thought to be the product of meiosis without a basidiocarp (Evans et al., 2002). The mycelial mass that populates the pod during the biotrophic phase following initial infection is reported to be in 
a haploid state, while the formation of dikaryotic mycelia is thought to coincide with the necrotrophic phase of the disease and leads to sporulation and completion of the life cycle (Evans et al., 2002). The trigger for the shift from the biotrophic to the necrotrophic phase is unknown so far. Possible triggers include developmental signals from the host or quorum sensing by the fungus (Newton et al., 2010). It is also established that single spore generated cultures which are dikaryotic can produce infective spores capable of establishing the biotrophic phase. It is in these spores that Evans et al. (2002) found evidence of a highly modified form of meiosis. An intriguing possibility is that $M$. roreri reproduces by meiosis leading to a haploid biotrophic mycelium which has nuclei that auto duplicate thus forming the dikaryotic necrotrophic mycelia. This process would insure homozygosity is maintained for every reproductive generation under most circumstances.

The two Costa Rican isolates from late 1970s and early 1980s (ATCC42952 and ATCC64239) showed 100\% sequence similarities with all the isolates collected in the country between 1999 and 2013, while the same genotype (Co20m, Co33, and E32) was also isolated from infected cacao pods in Colombia and Ecuador during 1999 and 2004. It clearly suggests that these particular $M$. roreri isolates were able to propagate clonally for more than three decades without recombination. During the movement of $M$. roreri into Central America apparently only one genotype was able to pass through, resulting in an obvious bottle neck. Similarly, it appears a single isolate crossed the Andes into Eastern Ecuador and then moved south toward Peru and Bolivia (Figure 4). Analysis of additional isolates should confirm this observation, although with time additional isolates may be introduced into these areas.

Whether a fungus reproduces clonally or sexually depends on various factors relating to its biology and distribution in space and time (Taylor et al., 1999). In the $M$. roreri sister taxon $M$. perniciosa, the presence of $A$ and $B$ mating type genes, normally associated with tetrapolar species, was used to demonstrate the evolution of self-compatibility in the presence of such genes (Kües and Navarro-González, 2010). Looking into the M. roreri genome, the presence of homeodomain transcription factors HD1 (XP_007858882) and HD2 (XP_007858883) along with nine potential pheromone receptors (XP_007851881, XP_007859042, XP_007849207, XP_007853337, XP_007854546, XP_007854545, XP_007854550, XP_007849212, and XP_007849206) indicates that it may also possess a tetrapolar mating system similar to $M$. perniciosa. Even though primarily homothallic Agaricomycetes have no obvious need for such mating type genes, they are widely present in homothallic species (Martinez et al., 2004; Kües and Navarro-González, 2010). In the case of $M$. roreri the fungus appears to have specific mechanisms to maintain a homokaryotic state. How and why this fungal pathogen is capable of functioning in a clonal state has yet to be determined but a series of heterokaryon incompatibility (het) proteins are upregulated during the necrotrophic phase prior to spore formation which could be responsible for the homokaryotic nuclear state. These up-regulated proteins are het-c, het-e, nacht, and WD40 domain proteins and NWD2 proteins (Meinhardt et al., 2014), all of which are integral components of the somatic self/non-self recognition system that preserves genetic identity and prevents heterokaryon formation between unlike individuals through programmed cell death (Van der Nest et al., 2014). Though the present finding confirms reproduction is primarily through homothallism in $M$. roreri isolates causing disease on cacao, the possibility of heterothallism for some isolates within this species remains. Further studies in terms of nuclear contents of the spores and germ tubes during infection, biotrophic mycelia and necrotrophic mycelia are needed. The SNPs identified here in can be used for determining any possible recombination between divergent isolates in induced mixed infection studies.

The limited nature of resistance/tolerance against this fungus in the cacao germplasm (Phillips-Mora et al., 2005; PhillipsMora, 2010) and the observed increases in disease losses in some tolerant clones in Costa Rica (Phillips-Mora et al., 2012; Bailey et al., 2014) raises the interesting question as to how a pathogen with low genetic diversity and limited genetic recombination potential can maintain such a highly virulent state. The answer likely lies in the unique origins of $M$. roreri, possibly as an endophyte, and its resulting genetic makeup (Meinhardt et al., 2014) combined with products of horizontal gene transfer (Tiburcio et al., 2010) and possibly viruses or retro elements acquired during evolution (Evans et al., 2013). It has also been suggested that the induction of $M$. roreri stress response genes during infection of tolerant clones may enable the fungus in overcoming cacao tolerance mechanisms (Bailey et al., 2014).

As the occurrence and distribution of genetically diverse groups in an area is the basis of designating centers of diversity and origin for the species, the present study suggest that Colombia is the likely center of origin for M. roreri, contradicting the previous hypothesis of Ecuador being the origin (Rorer, 1918; Briton-Jones, 1934; Erneholm, 1948). Phillips-Mora et al. (2007a) has also predicted the central/north-eastern Colombia as the origin. Based on the present SNP study, the upper Magdalena Valley, which contains 16 distinct genotypes out of which 10 are limited to this region showed the highest levels of genetic diversity within Colombia (Figure 4) and is most likely the center of origin of $M$. roreri. This was the area where FPR has been recorded on wild Theobroma by Baker et al. (1953), Cuatrecasas (1964) later identified it as T. gileri. Moreover, the presence of ancient populations of wild Theobroma and Herrania species known to be susceptible to $M$. roreri in this region of the Magdalena Valley of Colombia (Galán Gómez, 1947) further support the conclusion that this area is the center of origin of $M$. roreri. Based on the early reports from Ecuador and Colombia (Rorer, 1918; Baker et al., 1953), it seems M. roreri was endemic on wild Theobroma species of north-west Ecuador and western Colombia forests and that the cacao pathogen strain evolved in the latter region following a host jump, whilst the Ecuadorian $M$. roreri strains (var. gileri) never escaped from the sub-montane forests, and is non-pathogenic to cacao. It is probable that cacao was originally brought from its center of origin in the Upper Amazon and has been cultivated by the indigenous peoples of Magdalena Valley, Colombia for several thousands of years before it moved to other regions of Colombia (Bartley, 2005), and thus the crop has mingled with local Theobroma and Herrania species. This would have provided ample time for $M$. roreri to have 
jumped host and then evolved on cacao. Alternatively $M$. roreri might have evolved with a high degree of diversity within the wild Theobroma and Herrania species of Colombia and jumped multiple times to cacao after the commercial plantations started. Commercial cacao plantation of Colombia would have been at risk from the pathogen in the 19th century, hence the historical and catastrophic disease outbreaks reported in the 1850s with symptoms that resemble those of FPR (Ancízar, 1853; Baker et al., 1953; Phillips-Mora et al., 2007a). It also seems likely that the switch from the indigenous Nacional variety of western Ecuador to the more productive Forastero during the latter part of the 19th century (Rorer, 1918) led to the accidental importation of M. roreri from Colombia with disastrous consequences for the cacao industry and to the gradual abandonment of large-scale production of cacao in Ecuador (Evans, 1986). The previous suggestion of natural dispersal of $M$. roreri into Central America (Holliday, 1957) seems less likely and the movement of $M$. roreri into Central America along with the more recent occurrences in Peru and Bolivia probably resulted from a single introduction by humans as suggested by Phillips-Mora et al. (2007a).

Unlike the previously reported five genetic groups (PhillipsMora et al., 2007a), the distance based PCoA and dendrogram analysis carried out here, grouped the 172 isolates into two major phylogenetic groups, one being highly dispersed both in terms of genetic variation and geographical distance (Group $b$ ) while the other group (Group $a$ ) is mainly confined to Colombia, and has significant genetic diversity resulting in many unique isolates (Group $a$; Figure 3). The low bootstrap support for the four phylogenetic Sub-groups within Group $a$ was due to small number of SNPs involved in those differentiations. As each SNP is a unique event that can be tracked with certainty, the genetic differentiations here in is of high confidence. The phylogenetic Sub-group I is centered around the upper Magdalena Valley and crossed the Central Andes through the northern side and then moved south along the Cauca Valley. Similarly, Sub-groups II and IV moved west from upper Magdalena Valley and crossed the Western Andes and the moved south along the coast reaching Ecuador (Figures 3 and 4). On the other hand phylogenetic Sub-group III was able to cross the Eastern Andes. Similarly, isolates of phylogenetic Group $b$ were isolated from the upper Magdalena Valley. They moved North and West from the upper Magdalena Valley, while a few isolates were able to move south along the coast (Figure 4). In a previous finding by Phillips-Mora et al. (2007a), 12 Colombian isolates had been grouped into two genetic groups confined to central Colombia and Santander regions; the present study shows a more diverse picture of the pathogen in terms of distribution within and dispersal from the Santander regions. Since we now know $M$. roreri maintains a clonal state, we expect to see less indication of genetic drift associated with the movement from the pathogens center of origin. Instead, this study suggested dispersal of $M$. roreri clones from the upper Magdalena Valley over time and the subsequent localized genetic drift associated with these unique isolates and events.

It may be that natural dispersal started out on the wild Theobroma and Herrania hosts (Holliday, 1957; Evans, 1981) and then jumped to commercial cacao. Dispersal by the early civilizations and settlers is another probability especially if we consider the huge physical barrier created by the Andes within Colombia. The question remains, why isolates those have been successful in disseminating, show greater genetic diversity and essentially appear as out groups compared to the isolates of limited distribution from within Colombia and Ecuador. Fungal spores are the single most important part of the $M$. roreri life cycle when it comes to dispersion in time and space. Though comparison of spore shape and size of these two groups suggest no obvious difference (See Supplementary Figure S4), they might differ in composition of the compatible solutes and other protective proteins inside the spores which are influenced by the environmental conditions during their formation (Wyatt et al., 2013). For a clearer picture of genetic or geographic pattern of dispersion within Colombia, more isolates, especially from the regions other than upper Magdalena Valley, should be included in future studies. For population studies involving countries other than Colombia we need to incorporate more SNPs derived from comparing isolates collected in those countries due to their limited diversity and the clonal nature of SNP dispersal.

\section{Conclusion}

The current set of SNP markers developed for $M$. roreri can be widely used for population genetics and evolutionary studies of the pathogen and would be a great asset for breeding cacao tolerant against to FPR. The fact that $M$. roreri propagation is clonal or homothallic and the generation of new recombinants through sexual propagation is a comparatively rare event, if it occurs at all, has a huge implication on the breeding and disease management strategy against FPR. The present study also gives credence to the need for strict quarantine even in areas where FPR is endemic to stop the introduction of new $M$. roreri genotypes which might make the disease management more complicated. Being the probable center of origin and representing almost half of the entire genetic diversity, the upper Magdalena Valley of Colombia becomes the most important area in terms of FPR research. The establishment of breeding and screening programs in this area would assure new cacao germplasm was selected for tolerance against the widest $M$. roreri genetic base.

\section{Acknowledgments}

Work was funded by USDA-ARS. References to a company and/or product by the USDA are only for the purposes of information and do not imply approval or recommendation of the product to the exclusion of others that may also be suitable. USDA is an equal opportunity provider and employer. We thank Mr. Stephen Pinney and Dr. Barbara Sue Mischke (SPCL, USDA/ARS) for helping with Fluidigm system.

\section{Supplementary Material}

The Supplementary Material for this article can be found online at: http://journal.frontiersin.org/article/10.3389/fmicb. 2015.00850 


\section{References}

Ali, S. S., Melnick, R. L., Crozier, J., Phillips-Mora, W., Strem, M. D., Shao, J., et al. (2014). Successful pod infections by Moniliophthora roreri result in differential Theobroma cacao gene expression depending on the clone's level of tolerance. Mol. Plant Pathol. 15, 698-710. doi: 10.1111/mpp.12126

Ancízar, M. (1853). Peregrinacion de Alpha: Por Las Provincias del Norte de la Nueva Granada, en 1850-51. Bogotá: Imprenta de Echeverría Hermanos.

Bailey, B. A., Crozier, J., Sicher, R. C., Strem, M. D., Melnick, R., Carazzolle, M. F., et al. (2013). Dynamic changes in pod and fungal physiology associated with the shift from biotrophy to necrotrophy during the infection of Theobroma cacao by Moniliophthora roreri. Physiol. Mol. Plant Pathol. 81, 84-96. doi: 10.1016/j.pmpp.2012.11.005

Bailey, B. A., Melnick, R. L., Strem, M. D., Crozier, J., Shao, J., Sicher, R., et al. (2014). Differential gene expression by Moniliophthora roreri while overcoming cacao tolerance in the field. Mol. Plant Pathol. 15, 711-729. doi: $10.1111 / \mathrm{mpp} .12134$

Bailey, B. A., Strem, M. D., Bae, H., de Mayolo, G. A., and Guiltinan, M. J. (2005) Gene expression in leaves of Theobroma cacao in response to mechanical wounding, ethylene, and/or methyl jasmonate. Plant Sci. 168, 1247-1258. doi: 10.1016/j.plantsci.2005.01.002

Baker, R. E. D., Cope, F. W., Holliday, P. C., Bartley, B. G., and Taylor, J. (1953). “The Anglo-Colombian cacao collecting expedition," in Reprint Archives Cocoa Research, Vol. 1, ed. H. Toxopeus (Vienna, VA: American Cocoa Research Institute).

Barbazuk, W. B., Emrich, S. J., Chen, H. D., Li, L., and Schnable, P. S. (2007) SNP discovery via 454 transcriptome sequencing. Plant J. 51, 910-918. doi: 10.1111/j.1365-313X.2007.03193.x

Bartley, B. G. (2005). The Genetic Diversity of Cacao and Its Utilization. Wallingford: CABI. doi: 10.1079/9780851996196.0000

Bateman, R., Hidalgo, E., Garcia, J., Arroyo, C., Ten Hoopen, G., Adonijah, V., et al. (2005). Application of chemical and biological agents for the management of frosty pod rot (Moniliophthora roreri) in Costa Rican cocoa (Theobroma cacao). Ann. Appl. Biol. 147, 129-138. doi: 10.1111/j.1744-7348.2005.00012.x

Briton-Jones, H. R. (1934). The Diseases and Coring of Cacao. London: Macmillan \& Co. Ltd.

Cánovas, A., Rincon, G., Islas-Trejo, A., Wickramasinghe, S., and Medrano, J. F. (2010). SNP discovery in the bovine milk transcriptome using RNA-Seq technology. Mamm. Genome 21, 592-598. doi: 10.1007/s00335-010-9297-z

Carlile, M. J., Watkinson, S. C., and Gooday, G. W. (2001). "Chapter 5 - Genetic variation and evolution," in The Fungi, 2nd Edn, eds M. J. Carlile, S. C. Watkinson, and G. W. Gooday (London: Academic Press), 245-295.

Chepelev, I., Wei, G., Tang, Q., and Zhao, K. (2009). Detection of single nucleotide variations in expressed exons of the human genome using RNA-Seq. Nucleic Acids Res. 37, e106. doi: 10.1093/nar/gkp507

Cuatrecasas, J. (1964). "Cacao and its allies, a taxonomic revision of the genus Theobroma," in Contributions from the United States National Herbarium (Washington: Smithsonian Institution), 379-605.

Danecek, P., Auton, A., Abecasis, G., Albers, C. A., Banks, E., DePristo, M. A., et al. (2011). The variant call format and VCFtools. Bioinformatics 27, 2156-2158. doi: 10.1093/bioinformatics/btr330

de la Cruz, M. T., García, C. O., Ortiz, D. T., Aguilera, A. M., and Díaz, C. N. (2011). Temporal progress and integrated management of frosty pod rot (Moniliophthora roreri) of cocoa in Tabasco, Mexico. J. Plant Pathol. 93, 31-36.

Dieringer, D., and Schlötterer, C. (2003). Microsatellite analyser (MSA): a platform independent analysis tool for large microsatellite data sets. Mol. Ecol. Notes 3, 167-169. doi: 10.1046/j.1471-8286.2003.00351.x

DNASTAR. (1999). SeqMan II, v. 4.00. Madison, WI: DNASTAR, Inc.

Drenth, A., and Sendall, B. (2001). Practical Guide to Detection and Identification of Phytophthora. Brisbane: CRC for Tropical Plant Protection.

Enríquez, G., and Suarez, C. (1978). Monilia disease of cocoa in Costa Rica. Turrialba 28, 339-340

Erneholm, I. (1948). Cacao Production of South America. Göteborg: CR Holmqvists Boktryckeri $\mathrm{Ab}$.

Evans, H. (1981). "Pod rot of cacao caused by Moniliophthora (Monilia) roreri," in Phytopathological papers 24 (Kew: Commonwealth Mycological Institute), $1-44$.
Evans, H. (1986). A reassessment of Moniliophthora (Monilia) pod rot of cocoa. Cocoa Growers'. Bull 37, 34-43.

Evans, H. C. (2007). Cacao diseases-the trilogy revisited. Phytopathology 97, 1640-1643. doi: 10.1094/PHYTO-97-12-1640i

Evans, H., Bezerra, J., and Barreto, R. (2013). Of mushrooms and chocolate trees: aetiology and phylogeny of witches' broom and frosty pod diseases of cacao. Plant Pathol. 62, 728-740. doi: 10.1111/ppa.12010

Evans, H., Krauss, U., Rios Rutz, R., Zecevich Acosta, T., and Arevalo-Gardini, E. (1998). Cocoa in Peru. Cocoa Growers'. Bulletin 51, 7-22.

Evans, H. C., Holmes, K. A., Phillips, W., and Wilkinson, M. J. (2002). What's in a name: Crinipellis, the final resting place for the frosty pod rot pathogen of cocoa? Mycologist 16, 148-152. doi: 10.1017/S0269915X02004093

Evans, H. C., Stalpers, J. A., Samson, R. A., and Benny, G. L. (1978). On the taxonomy of Monilia roreri, an important pathogen of Theobroma cacao in South America. Can. J. Bot. 56, 2528-2532. doi: 10.1139/b78-305

Galán Gómez, M. (1947). Geografía económica de Colombia, Tomo VIII. Bucaramanga: Santander Imprenta departamental.

Garvin, M., Saitoh, K., and Gharrett, A. (2010). Application of single nucleotide polymorphisms to non-model species: a technical review. Mol. Ecol. Resour. 10, 915-934. doi: 10.1111/j.1755-0998.2010.02891.x

Hernández, T. A., Aranzazu, F., Arevalo, E., and Rios, R. (1990). La moniliasis del cacao en el peru. Agrotropica 2, 56-58.

Hidalgo, E., Bateman, R., Krauss, U., ten Hoopen, M., and Martínez, A. (2003). A field investigation into delivery systems for agents to control Moniliophthora roreri. Eur. J. Plant Pathol. 109, 953-961. doi: 10.1023/B:EJPP.0000003746.16934.e2

Holliday, P. (1957). Spread of pod rot of cocoa. Commonwealth Phytopatholog News 3, 12.

Holliday, P. (1971). Some tropical plant pathogenic fungi of limited distribution. Rev. Plant Pathol. 50, 337-348.

Krauss, U., Hidalgo, E., Bateman, R., Adonijah, V., Arroyo, C., García, J., et al. (2010). Improving the formulation and timing of application of endophytic biocontrol and chemical agents against frosty pod rot (Moniliophthora roreri) in cocoa (Theobroma cacao). Biolog. Control 54, 230-240. doi: 10.1016/j.biocontrol.2010.05.011

Krauss, U., and Soberanis, W. (2001). Biocontrol of cocoa pod diseases with mycoparasite mixtures. Biolog. Control 22, 149-158. doi: 10.1006/bcon.2001.0956

Kües, U., and Navarro-González, M. (2010). Mating-type orthologous genes in the primarily homothallic Moniliophthora perniciosa, the causal agent of Witches' Broom Disease in cacao. J. Basic Microbiol. 50, 442-451. doi: 10.1002/jobm.201000013

Langmead, B., Trapnell, C., Pop, M., and Salzberg, S. L. (2009). Ultrafast and memory-efficient alignment of short DNA sequences to the human genome. Genome Biol. 10, R25. doi: 10.1186/gb-2009-10-3-r25

Larkin, M. A., Blackshields, G., Brown, N., Chenna, R., McGettigan, P. A., McWilliam, H., et al. (2007). Clustal W and Clustal X version 2.0. Bioinformatics 23, 2947-2948. doi: 10.1093/bioinformatics/btm404

Li, H., Handsaker, B., Wysoker, A., Fennell, T., Ruan, J., Homer, N., et al. (2009). The sequence alignment/map format and SAMtools. Bioinformatics 25 2078-2079. doi: 10.1093/bioinformatics/btp352

Martinez, D., Larrondo, L. F., Putnam, N., Gelpke, M. D. S., Huang, K., Chapman, J., et al. (2004). Genome sequence of the lignocellulose degrading fungus Phanerochaete chrysosporium strain RP78. Nat. Biotechnol. 22, 695-700. doi: $10.1038 /$ nbt0704-899b

Meinhardt, L. W., Costa, G. G., Thomazella, D. P., Teixeira, P. J., Carazzolle, M. F., Schuster, S. C., et al. (2014). Genome and secretome analysis of the hemibiotrophic fungal pathogen, Moniliophthora roreri, which causes frosty pod rot disease of cacao: mechanisms of the biotrophic and necrotrophic phases. BMC Genomics 15:164. doi: 10.1186/1471-2164-15-164

Meyer, E., Aglyamova, G. V., Wang, S., Buchanan-Carter, J., Abrego, D., Colbourne, J. K., et al. (2009). Sequencing and de novo analysis of a coral larval transcriptome using 454 GSFlx. BMC Genomics 10:219. doi: 10.1186/14712164-10-219

Nei, M., Tajima, F., and Tateno, Y. (1983). Accuracy of estimated phylogenetic trees from molecular data. J. Mol. Evol. 19, 153-170. doi: 10.1007/BF02 300753 
Newton, A. C., Fitt, B. D., Atkins, S. D., Walters, D. R., and Daniell, T. J. (2010). Pathogenesis, parasitism and mutualism in the trophic space of microbe-plant interactions. Trends Microbiol. 18, 365-373. doi: 10.1016/j.tim.2010.06.002

Ng, S. B., Turner, E. H., Robertson, P. D., Flygare, S. D., Bigham, A. W., Lee, C., et al. (2009). Targeted capture and massively parallel sequencing of 12 human exomes. Nature 461, 272-276. doi: 10.1038/nature08250

Novaes, E., Drost, D. R., Farmerie, W. G., Pappas, G. J., Grattapaglia, D., Sederoff, R. R., et al. (2008). High-throughput gene and SNP discovery in Eucalyptus grandis, an uncharacterized genome. BMC Genomics 9:312. doi: 10.1186/14712164-9-312

Orellana, R. G. (1956). Occurrence of Monilia pod rot and other cacao diseases in eastern Panama. FAO Plant Protec. Bull. 4, 168-169.

Peakall, R., and Smouse, P. E. (2006). GENALEX 6: genetic analysis in Excel. Population genetic software for teaching and research. Mol. Ecol. Notes 6, 288-295.

Peakall, R., and Smouse, P. E. (2012). GenAlEx 6.5: genetic analysis in Excel. Population genetic software for teaching and research-an update. Bioinformatics 28, 2537-2539.

Peakall, R., Smouse, P. E., and Huff, D. (1995). Evolutionary implications of allozyme and RAPD variation in diploid populations of dioecious buffalograss Buchloe dactyloides. Mol. Ecol. 4, 135-148. doi: 10.1111/j.1365294X.1995.tb00203.x

Phillips-Mora, W. (2010). "The cacao breeding program at CATIE, Costa Rica," in Proceedings of the 18th Plant and Animal Genome Conference, San Diego, 115.

Phillips-Mora, W., Aime, M., and Wilkinson, M. J. (2007a). Biodiversity and biogeography of the cacao (Theobroma cacao) pathogen Moniliophthora roreri in tropical America. Plant Pathol. 56, 911-922. doi: 10.1111/j.13653059.2007.01646.x

Phillips-Mora, W., Ortiz, C. F., and Aime, M. C. (2007b). "Fifty years of frosty pod rot in Central America: chronology of its spread and impact from Panama to Mexico," in Proceedings of the 15th International Cocoa Research Conference, Vol. I, San José, 1039-1047.

Phillips-Mora, W., Arciniegas Leal, A., Mata Quirós, A., and Motamayor-Arias, J. C. (2012). "Catálogo de clones de cacao seleccionados por el CATIE para siembras comerciales," in Manual técnico no.105 (Turrialba: CATIE).

Phillips-Mora, W., Castillo, J., Krauss, U., Rodríguez, E., and Wilkinson, M. J. (2005). Evaluation of cacao (Theobroma cacao) clones against seven Colombian isolates of Moniliophthora roreri from four pathogen genetic groups. Plant Pathol. 54, 483-490. doi: 10.1111/j.1365-3059.2005.01210.x

Phillips-Mora, W., Coutiño, A., Ortiz, C., López, A., Hernández, J., and Aime, M. (2006). First report of Moniliophthora roreri causing frosty pod rot (moniliasis disease) of cocoa in Mexico. Plant Pathol. 55, 584-584. doi: 10.1111/j.13653059.2006.01378.x

Plotree, D., and Plotgram, D. (1989). PHYLIP-phylogeny inference package (version 3.2). Cladistics 5, 163-166.

Quinn, E. M., Cormican, P., Kenny, E. M., Hill, M., Anney, R., Gill, M., et al. (2013). Development of strategies for SNP detection in RNA-seq data: application to lymphoblastoid cell lines and evaluation using 1000 Genomes data. PLoS ONE 8:e58815. doi: 10.1371/journal.pone.0058815

Rambaut, A. (2009). FigTree: Tree Figure Drawing Tool, Version 1.3.1. Edinburgh: Institute of Evolutionary Biology, University of Edinburgh.

Rorer, J. B. (1918). Enfermedades y Plagas del Cacao en el Ecuador y Metodos Modernos Apropiados al Cultivo del Cacao, Informe Presentado al Presidente y Miembros de la Asociación de Agricultores del Ecuador. Guayaquil: Asociacioìn de agricultores del Ecuador.
Saitou, N., and Nei, M. (1987). The neighbor-joining method: a new method for reconstructing phylogenetic trees. Mol. Biol. Evol. 4, 406-425.

Salem, M., Vallejo, R. L., Leeds, T. D., Palti, Y., Liu, S., Sabbagh, A., et al. (2012). RNA-Seq identifies SNP markers for growth traits in rainbow trout. PLoS ONE 7:e36264. doi: 10.1371/journal.pone.0036264

Sánchez, C. C., Smith, T. P., Wiedmann, R. T., Vallejo, R. L., Salem, M., Yao, J., et al. (2009). Single nucleotide polymorphism discovery in rainbow trout by deep sequencing of a reduced representation library. BMC Genomics 10:559. doi: 10.1186/1471-2164-10-559

Suh, Y., and Vijg, J. (2005). SNP discovery in associating genetic variation with human disease phenotypes. Mutat. Res. 573, 41-53. doi: 10.1016/j.mrfmmm.2005.01.005

Taylor, J., Jacobson, D., and Fisher, M. (1999). The evolution of asexual fungi: reproduction, speciation and classification. Annu. Rev. Phytopathol. 37, 197246. doi: 10.1146/annurev.phyto.37.1.197

Tiburcio, R. A., Costa, G. G. L., Carazzolle, M. F., Mondego, J. M. C., Schuster, S. C., Carlson, J. E., et al. (2010). Genes acquired by horizontal transfer are potentially involved in the evolution of phytopathogenicity in Moniliophthora perniciosa and Moniliophthora roreri, two of the major pathogens of cacao. J. Mol. Evol. 70, 85-97. doi: 10.1007/s00239-009-9311-9

Tollenaere, C., Susi, H., Nokso-Koivisto, J., Koskinen, P., Tack, A., Auvinen, P., et al. (2012). SNP design from 454 sequencing of Podosphaera plantaginis transcriptome reveals a genetically diverse pathogen metapopulation with high levels of mixed-genotype infection. PLoS ONE 7:e52492. doi: 10.1371/journal.pone.0052492

Van der Nest, M., Olson, Å, Lind, M., Velez, H., Dalman, K., Durling, M. B., et al. (2014). Distribution and evolution of het gene homologs in the basidiomycota. Fungal Genet. Biol 64, 45-57. doi: 10.1016/j.fgb.2013.12.007

Vidal, R. O., Nascimento, L. C. D., Maurício Costa Mondego, J., Amarante Guimarães Pereira, G., and Falsarella Carazzolle, M. (2012). Identification of SNPs in RNA-seq data of two cultivars of Glycine max (soybean) differing in drought resistance. Genet. Mol. Biol. 35, 331-334. doi: 10.1590/S141547572012000200014

Wang, J., Lin, M., Crenshaw, A., Hutchinson, A., Hicks, B., Yeager, M., et al. (2009). High-throughput single nucleotide polymorphism genotyping using nanofluidic Dynamic Arrays. BMC Genomics 10:561. doi: 10.1186/1471-216410-561

Wang, X.-R., and Szmidt, A. E. (2000). "Population genetic analysis of pathogenic forest fungi," in Molecular Biology of Woody Plants, eds S. M. Jain and S. C. Minocha (Heidelberg: Springer), 491-520.

Wyatt, T. T., Wösten, H., and Dijksterhuis, J. (2013). Fungal spores for dispersion in space and time. Adv. Appl. Microbiol 85, 42-91. doi: 10.1016/B978-0-12407672-3.00002-2

Conflict of Interest Statement: The authors declare that the research was conducted in the absence of any commercial or financial relationships that could be construed as a potential conflict of interest.

Copyright (c) 2015 Ali, Shao, Strem, Phillips-Mora, Zhang, Meinhardt and Bailey. This is an open-access article distributed under the terms of the Creative Commons Attribution License (CC BY). The use, distribution or reproduction in other forums is permitted, provided the original author(s) or licensor are credited and that the original publication in this journal is cited, in accordance with accepted academic practice. No use, distribution or reproduction is permitted which does not comply with these terms. 